\title{
PROBLEMATIKA PENERAPAN SISTEM NAZHARIYYAH AL WAHDAH PADA PEMBELAJARAN BAHASA ARAB DI MADRASAH ALIYAH SE-KOTA METRO TAHUN 2018
}

\author{
Novita Rahmi \\ Institut Agama Islam Negeri (IAIN) Metro \\ Jl. Ki Hajar Dewantara, Iringmulyo, Metro Timur., \\ Kota Metro, Lampung 34381 \\ e-mail: novitarahmi85@yahoo.co.id
}

\begin{abstract}
This study aims to determine the problems and solutions to the application of the Nazhariyah Al Wahdah system in learning Arabic in the Aliyah Madrasah in Metro City in 2018. This research is a qualitative case study conducted in 3 Aliyah Madrasas in Metro City: MAN 1, MA Muhammadiyah, and MA Raudhatut Thalibin. The researcher uses interactive model data analysis. Based on data collection techniques: In-depth interviews, documentation, and participatory observation, the researchers concluded that these problems occur due to inadequate time allocation and unavailability of language laboratories. And professional teachers in the field of Arabic and the existence of a language environment are the solution to this problem.
\end{abstract}

Keywords: Nazhariyah Al Wahdah System, Learning Arabic.

\begin{abstract}
Abstrak
Adapun tujuan penelitian adalah untuk mengetahui problematika dan solusi penerapan sistem Nazhariyah Al Wahdah pada pembelajaran Bahasa Arab di Madrasah Aliyah se-Kota Metro tahun 2018. Penelitian ini merupakan penelitian kualitatif studi kasus yang dilakukan di 3 Madrasah Aliyah Kota Metro: MAN 1, MA Muhammadiyah, dan MA Raudhatut Thalibin. Peneliti menggunakan analisa data model interaktif. Berdasarkan teknik pengumpulan data: Wawancara mendalam, dokumentasi, dan observasi partisipatif, peneliti menyimpulkan bahwa problematika ini terjadi karena alokasi waktu yang tidak memadai dan tidak tersedianya laboratorium bahasa. Dan guru yang profesional di bidang bahasa Arab dan adanya lingkungan bahasa menjadi solusi dari permasalahan ini.
\end{abstract}

Kata Kunci: Sistem Nazhariyah Al-Wahdah, Pembelajaran Bahasa Arab. 


\section{A. Pendahuluan}

Bahasa Arab merupakan mata pelajaran yang diarahkan untuk memahami sumber ajaran agama Islam yaitu kitab suci Al-Qur'an dan Hadits, sehingga diyakini dapat membentuk peserta didik menjadi manusia yang beriman dan bertakwa kepada Tuhan Yang Maha Esa serta berakhlak mulia. Hal ini sejalan dengan tujuan pendidikan nasional yang tertera dalam Pasal 3 UndangUndang No.20 tahun 2003 tentang Sistem Pendidikan Nasional. ${ }^{1}$

Pembelajaran bahasa Arab di Indonesia ini menghadapi berbagai kendala dan problematika. Untuk mengatasi berbagai problematika tersebut, salah satu cara yang bisa dilakukan yaitu dengan memahami sistem pembelajaran bahasa Arab sebagai landasan dalam memahami praktik pembelajaran bahasa Arab. Ada dua sistem pokok yang telah berkembang dalam pembelajaran bahasa Arab, yaitu sistem terpisah (cabang) dan terpadu (kesatuan/integrasi). Atau di dalam bahasa Arab dikenal dengan istilah Nazhariyyah al Furu' (terpisah) dan Nazhariyyah al Wahdah (terpadu). ${ }^{2}$

1 Menteri Agama Republik Indonesia, “Peraturan Menteri Agama Republik Indonesia No. 912 Tahun 2013 tentang Kurikulum Madrasah 2013 Mata Pelajaran Pendidikan Agama Islam dan Bahasa Arab," 2013, h. 4 Tujuan pendidikan nasional, Pasal 3 Undang-Undang No.20 tahun 2003 tentang Sistem Pendidikan Nasional, bahwa: Pendidikan nasional berfungsi mengembangkan kemampuan dan membentuk watak serta peradaban bangsa yang bermartabat dalam rangka mencerdaskan kehidupan bangsa, bertujuan untuk mengembangkan potensi peserta didik agar menjadi manusia yang beriman dan bertakwa kepada Tuhan Yang Maha Esa, berakhlak mulia, sehat, berilmu, cakap, kreatif, mandiri dan menjadi warga negara yang demokratis serta bertanggung jawab.

2 Aziz Fachrurrozi dan Erta Mahyuddin, Teknik Pembelajaran Bahasa Arab (Bandung: Pustaka Cendikia Utama, 2011), h. 14. Nazhariyyah al Furu' (terpisah) adalah membagi bahasa menjadi beberapa bagian yang terpisah, setiap cabang bahasa mempunyai silabus, buku, metode,dan alokasi waktu tertentu. Di lembaga pendidikan Indonesia, sebagian besar sistem ini diterapkan pada pondok pesantren. Adapun Nazhariyyah al Wahdah (terpadu) adalah bahwa kita melihat bahasa sebagai satu kesatuan yang berhubungan erat, bukan sebagai cabang-cabang yang terpisah dan berbeda. Setiap unit pelajaran membahas satu pokok bahasan yang dijabarkan dalam beberapa sub pokok bahasan, satu topik/judul pembahasan meliputi seluruh aspek kompetensi bahasa. 
Biasanya sistem ini diterapkan pada sekolah negeri di Indonesia: Madrasah Ibtidaiyah, madrasah Tsanawiyah, dan madrasah Aliyah. Riset terkait sistem Nazhariyyah al Wahdah telah banyak dilakukan. Tesis dengan judul: Implementasi Nazhariyyah al Wahdah dalam Pembelajaran Bahasa Arab di SMA Islam Pekalongan. Oleh: Damir tahun 2013 IAIN Walisongo, yang bertujuan untuk mengetahui bagaimana penerapan sistem Nazhariyyah al Wahdah di SMA Islam Pekalongan yang di dalamnya mencakup tujuan pembelajaran, guru, materi pembelajaran, dan evaluasi pembelajaran. ${ }^{3}$

Skripsi dengan judul: Penerapan sistem Nazhariyyah al Wahdah dalam Pembelajaran Bahasa Arab di Pondok Modern As Salam Kranggan Temanggung Jawa Tengah. Oleh: Mudini UIN Sunan Kalijaga tahun 2003 diposting 2013, yang bertujuan untuk mengetahui sejauh mana penerapan sistem Nazhariyyah al Wahdah pada santri di Pondok Modern As Salam Temanggung, serta mengetahui solusi yang sesuai dengan problematika yang dihadapi. $^{4}$

Penelitian senada dengan judul: Sistematika Penerapan sistem Nazhariyyah al Wahdah di Madrasah Tsanawiyah dan MAN di Kota Langsa Provinsi Aceh. Oleh Syafieh dan Ibn Khaldun, yang bertujuan untuk mengetahui apakah penerapan sistem Nazhariyyah al Wahdah dalam pembelajaran bahasa Arab sudah terintegrasi dengan baik atau belum.

Pembelajaran bahasa Arab pada saat ini belum mencapai tujuan yang maksimal. Peneliti menemukan data di lapangan bahwa ketika mendengar kata "Bahasa Arab" siswa beranggapan bahasa Arab adalah mata pelajaran yang

\footnotetext{
${ }^{3}$ Damir, "Implementasi Naẓariyah al-Wahdah dalam Pembelajaran Bahasa Arab di SMA Islam Pekalongan" (Tesis, IAIN Walisongo, 2013), http://eprints.walisongo.ac.id/1481/.

${ }^{4}$ Mudini, "Penerapan Nadzariyatul Wahdah Dalam Pengajaran Bahasa Arab Di Pondok Modern Assalam Kranggan Temanggung Jawa Tengah" (Skripsi, UIN Sunan Kalijaga Yogyakarta, 2003), http://digilib.uin-suka.ac.id/9576/.
} 
sulit untuk dikuasai. Fakta ini diperkuat dengan adanya input mahasiswa pada jurusan Pendidikan Bahasa Arab IAIN Metro. Mereka masih terkendala memahami mata kuliah yang berkaitan dengan bahasa Arab, mereka lebih memilih menggunakan bahasa Indonesia baik secara lisan maupun tulisan. Mereka juga lebih memilih membaca buku rujukan berbahasa Indonesia dari pada buku rujukan berbahasa Arab. Hal ini tentunya akan memperbesar problematika pembelajaran bahasa Arab ke depannya. Peneliti juga mengadakan survey ke MAN 1 Metro. Para siswa belum mampu menguasai semua bagian-bagian materi pada pelajaran Bahasa Arab secara maksimal yang terdiri dari Mufrodat, Istima', Hiwar, Tarkib, Qira'ah, dan Kitabah. Dari 6 bagian ini, Istima' dan Tarkib menjadi materi yang paling susah untuk dikuasai oleh siswa.

\section{B. Kajian Teori}

\section{Sistem Nazhariyah al Wahdah}

a) Pengertian Sistem Nazariyah al-Wahdah

Nazariyah al-wahdah (All In One System) memandang bahasa sebagai bahasa, bahasa merupakan alat komunikasi antara manusia, hal ini merupakan suatu keutuhan dan kebulatan, kait mengait atau saling berhubungan. ${ }^{5}$ Yang dimaksud dengan sistem pembelajaran bahasa Arab di sini adalah bagaimana cara melihat bagian-bagian bahasa Arab dan bagaimana cara mengajarkan bagian-bagian tersebut. Sistem Nazhariyyah al Wahdah disebut juga dengan sistem integrasi/ terpadu/

${ }^{5}$ Dalam kesusasteraan klasik Islam, teori ini pernah diperkenalkan oleh Abul Abbas Al Mubarrad (pakar ilmu madzhab Basrah, 826-898) dalam kitabnya Al-Kamil. Teori ini tidak membenarkan pengkhususan jam-jam pelajaran khusus untuk suatu cabang ilmu bahasa. Naz̧ariyah al-Wahdah mulai diterapkan di Indonesia sejak ditetapkannya Keputusan Menteri Agama No. 75 Tahun 1975. Mulanya dilontarkan oleh H. A. Mukti Ali saat menjabat sebagai Menteri Agama waktu itu. 
all in one system. Sistem ini mengandung makna bahwa pembelajaran bahasa Arab adalah bahasa merupakan satu kesatuan yang berkaitan erat, dan bukan disajikan dalam bentuk terpisah (bercabang-cabang). ${ }^{6}$

Jadi bisa dikatakan bahwa penerapan sistem ini mengajarkan bahasa secara terpadu dalam satu mata pelajaran. Berbagai unsur bahasa dan keterampilan berbahasa disajikan secara terintegrasi. Unsur bahasa adalah bagian-bagian dari bahasa yang mempunyai aturanaturan tersendiri, yang meliputi: tata bunyi (fonologi/ ashwat), tata kalimat (nahwu), dan kosa kata (mufradat). Sedangkan keterampilan berbahasa adalah kemampuan menggunakan bahasa sebagai alat komunikasi baik lisan maupun tulis, yang meliputi keterampilan menyimak, berbicara, membaca, dan menulis.

\section{b) Kelebihan dan Kekurangan Nazariyah al-Wahdah}

Kelebihan sistem nazhariyah al Wahdah ini erat kaitannya dengan dasar penerapannya pada pembelajaran bahasa Arab. Adapun kelebihan dari sistem ini antara lain:

1) Menampilkan materi pelajaran bahasa secara utuh dan tidak terpisah-pisah sehingga para pelajar tidak dihadapkan pernakpernik ilmu tentang bahasa yang pada umumnya membingungkan. Karena itulah Nadzariyatul Wahdah berupaya menampilkan pelajaran bahasa asing (bahasa Arab) secara sederhana dan praktis sehingga bahasa asing tidak terkesan sulit.

2) Nadzariyatul Wahdah ini sangat mendukung para pengajar dalam menyampaikan pelajaran kepada siswa, terutama tujuannya agar siswa bisa berkomunikasi dengan bahasa asing. ${ }^{7}$

\footnotetext{
${ }^{6}$ Zulhannan, Paradigma Baru Pembelajaran Bahasa Arab (Bandar Lampung: An-
} Nur Press, 2004), h. 15.

7 Laily Sholihatin, “Nadzariyatul Furu' dan Nadzariyatul Wahdah” (Makalah, 2013). 
Dalam pendapat lain, dijelaskan bahwa kelebihan sistem terpadu ini adalah landasan teoritisnya yang kuat, baik teori psikologi, teori kebahasaan maupun teori kependidikan. Dari sisi psikologi, sistem terpadu ini sesuai dengan cara kerja otak dalam memandang sesuatu, yaitu dari global atau keseluruhan baru ke bagian-bagiannya. Variasi bahan atau variasi teknik penyajiannya bisa menghindarkan siswa dari kejenuhan. Dari segi teori kebahasaan, sistem terpadu sesuai dengan realita bahasa yang memadukan berbagai unsur dan keterampilan bahasa secara utuh. Dari segi kependidikan, sistem terpadu ini menjamin terwujudnya pertumbuhan kemampuan bahasa secara seimbang, karena semuanya ditangani dalam situasi dan kondisi yang sama, tidak dipengaruhi oleh keberagaman semangat dan kemampuan para guru. ${ }^{8}$

Selain kelebihan, sistem ini juga memiliki beberapa kekurangan, antara lain:

1) Pendangkalan pengetahuan murid dalam pengetahuan ilmu bahasa terutama ilmu nahwu, ilmu sharf dan balaghah. Dalam sejarah perkembangan bahasa Arab, pelajaran tersebut sudah menjadi ilmu sendiri.

2) Untuk tujuan keagamaan dalam pengkajian bahasa Arab, seperti memahami Al Quran dan Al Hadis masih kurang memungkinkan maka teori ini berlaku diterapkan sampai mushlah mutaqoddimah ilmu qowaid dan balaghah sebaiknya diajarkan kepada murid sebagai ilmu yang berdiri sendiri.

${ }^{8}$ Syamsuddin Asyrofi, Metodologi Pembelajaran Bahasa Arab (Yogyakarta: Idea Press, 2010), h. 115. 
3) Tidaklah mudah menyusun buku bacaan pelajaran bahasa Arab dengan teori ini, sebab buku bacaan harus memperhatikan sekuensi perkembangan gramatik, kosa kata, uslub dan sebagainya.

4) Jika diterapkan pada siswa tingkat lanjut (mutaqaddimin) kurang dapat memenuhi kepentingan pendalaman unsur bahasa atau keterampilan berbahasa tertentu yang memang menjadi kebutuhan nyata mereka. ${ }^{9}$

\section{c) Materi/ Sub Pembahasan pada Pelajaran Bahasa Arab}

\section{Berlandaskan Sistem Nazhariyyah al Wihdah}

Pembelajaran bahasa Arab di madrasah pada umumnya menggunakan sistem ini, sedangkan pembelajaran bahasa Arab di pesantren umumnya menggunakan sistem terpisah. Konsekuensi penggunaan sistem ini adalah semua komponen pelajaran yang terkait dengan bahasa Arab disajikan dalam satu mata pelajaran dengan buku dars yang menjelaskan semua aspek bahasa yang diprogramkan. Setiap pembahasan/unit pada buku tersebut biasanya meliputi satu pokok bahasan yang terdiri dari empat atau lima komponen, yaitu: Al Hiwar / dialog, Al Qira-ah / membaca, Al qawa'id / at tarkib / tata bahasa, dan Al kitabah / menulis.

Dengan materi pelajaran yang didesain sedemikian rupa, para guru yang mengampu mata pelajaran ini dianjurkan menggunakan metode eklektik (at thariqah al intiqaiyyah), dengan beberapa teknik seperti tanya jawab, dramatisasi, peragaan, penugasan, drill, dan mengungkapkan kembali isi wacana.

\footnotetext{
${ }^{9}$ Asyrofi, h. 115.
} 


\section{Pembelajaran Bahasa Arab}

\section{a) Tujuan Pembelajaran Bahasa Arab}

Pembelajaran bahasa diperlukan agar seseorang dapat berkomunikasi dengan baik dan benar dengan sesamanya dan lingkungannya, baik secara lisan maupun tulisan. Tujuan pembelajaran bahasa adalah untuk menguasai ilmu bahasa dan kemahiran berbahasa Arab, seperti muthola'ah, muhadatsah, insya', nahwu dan sharaf, sehingga memperoleh kemahiran berbahasa yang meliputi empat aspek kemahiran, yaitu kemahiran menyimak, berbicara, membaca, dan menulis.

Departemen Agama menjelaskan bahwa tujuan umum pembelajaran bahasa Arab adalah:

1) Untuk dapat memahami al-Quran dan hadist sebagai sumber hukum ajaran Islam.

2) Untuk dapat memahami buku-buku agama dan kebudayaan Islam yang ditulis dalam bahasa Arab.

3) Untuk dapat berbicara dan mengarang dalam bahasa Arab.

4) Untuk dapat digunakan sebagai alat pembantu keahlian lain (supplementary).

5) Untuk membina ahli bahasa Arab, yakni benar-benar profesional. $^{10}$

\section{b) Ruang lingkup Pembelajaran Bahasa Arab}

Secara teori ilmu bahasa Arab itu terdiri dari:

1) Unsur/ Komponen Bahasa Arab

Dalam pandangan banyak ahli bahasa, bahasa dianggap terdiri dari bagian-bagian yang dapat dipisahkan dan dibedakan satu dari

\footnotetext{
${ }^{10}$ Najieb Taufiq, “Tujuan Pembelajaran Bahasa Arab," diakses 24 Juni 2019, http://najiebtaufiq.blogspot.com/2012/06/tujuan-pembelajaran-bahasa-arab.html.
} 
yang lainnya. Bagian-bagian yang dikenal sebagai unsur/komponen bahasa itu terdiri dari bunyi bahasa (aswat), kosakata (mufradat) dan tata bahasa (shorof/nahwu/tarkib). Penguasaan atas unsur/komponen bahasa Arab dianggap merupakan bagian dari pembentukan kemampuan berbahasa Arab. Oleh karena itu, pengajaran bahasa Arab yang sasaran kemampuannya berbahasa Arab juga meliputi pengajaran bunyi bahasa, pengajaran kosakata, dan pengajaran tata bahasa. ${ }^{11}$

2) Kompetensi-Kompetensi Bahasa Arab

Ada 4 keterampilan bahasa Arab: keterampilan menyimak (مهارة الاستماع), berbicara (مهارة الكلام), membaca (مهارة القراءة), dan menulis (مهارة الكتابة). Keterampilan menyimak dan membaca disebut dengan keterampilan pasif-reseptif, yaitu inisiatif untuk berkomunikasi berasal dari luar dirinya/bukan dari dirinya sendiri. Sedangkan keterampilan berbicara dan menulis disebut dengan keterampilan aktif-produktif, karena inisiatif dalam berkomunikasi dimulai dari diri sendiri, bukan dari orang lain.

3) Problem Kebahasaan dan Nonkebahasaan pada Pembelajaran Bahasa Arab

Problem kebahasaan adalah persoalan-persoalan yang dihadapi siswa atau pembelajaran yang terkait langsung dengan bahasa yang sedang dipelajari, yaitu kesulitan-kesulitan yang dihadapi siswa dalam proses pembelajaran yang diakibatkan oleh karakteristik bahasa Arab itu sendiri sebagai bahasa asing bagi siswa indonesia, seperti problem bunyi (ashwat arabiyah), problem kosakata (mufrodat), dan problem tata kalimat (tarakib, qawaid dan $\left.i^{\prime} r a b\right) .{ }^{12}$

\footnotetext{
${ }^{11}$ Fachrurrozi dan Mahyuddin, Teknik Pembelajaran Bahasa Arab, h. 20.

${ }^{12}$ Fachrurrozi dan Mahyuddin, h. 4.
} 
Dari uraian di atas dapat disimpulkan bahwa problem kebahasaan tersebut mencakup materi pembelajaran bahasa Arab atau dapat dikatakan sebagai teori-teori yang dipelajari dalam bahasa.

Berbeda halnya dengan problem non kebahasaan, problem ini mencakup karakteristik fisiologis (pribadi dan lingkungan peserta didik) yang terdiri dari: Umur, jenis kelamin, pengalaman prasekolah, dan kemampuan sosial-ekonomi orang tua. Karakteristik psikologis terdiri dari: tingkat kecerdasan, kreativitas, bakat dan minat, pengetahuan dasar dan prestasi terdahulu, motivasi belajar, dan sikap belajar. ${ }^{13}$

\section{Metode Penelitian}

\section{Jenis Penelitian}

Jenis penelitian ini adalah penelitian kualitatif interaktif studi kasus (case study). Jenis penelitian ini diarahkan untuk menghimpun data, mengambil makna, memperoleh pemahaman dari sebuah kasus.

\section{Sampel/ Narasumber/ Partisipan/ Informan}

Sampel pada penelitian ini disebut juga sebagai nara sumber atau partisipan atau informan. Teknik sampling yang digunakan peneliti adalah purposive sampling (pengambilan sampel dengan pertimbangan tertentu). ${ }^{14}$ Adapun sampel/ narasumber/ partisipan/ informan pada penelitian ini adalah: Guru bahasa Arab di Madrasah Aliyah se-Kota Metro, dan sejumlah siswa di Madrasah Aliyah se-Kota Metro.

\footnotetext{
${ }^{13}$ Iskandarwassid dan Dadang Suhendar, Strategi Pembelajaran Bahasa (Bandung: PT. Remaja Rosdakarya, 2011), h. 128.

${ }^{14}$ Sugiyono, Metode Penelitian Kuantitatif Kualitatif dan R\&D (Bandung: Alfabeta, 2009), h. 218.
} 


\section{Teknik Pengumpulan Data}

Peneliti menggunakan teknik pengumpulan data:

a) Wawancara mendalam, peneliti mewawancarai informan yang terdiri dari Guru bahasa Arab di Madrasah Aliyah se-Kota Metro, dan sejumlah siswa di Madrasah Aliyah se-Kota Metro.

b) Observasi partisipatif, peneliti melihat langsung proses belajar mengajar bahasa Arab sehingga peneliti dapat mengamati peran guru, metode, media, dan evaluasi yang benar-benar terjadi dalam pembelajaran bahasa Arab.

c) Dokumentasi, peneliti mencari data tentang profil/sejarah sekolah, jumlah jam pelajaran bahasa Arab, materi bahasa Arab, dan lainlain.

\section{Analisis Data}

Peneliti menggunakan analisis data model interaktif yang dikemukakan oleh Miles dan Huberman, dengan tahapan sebagai berikut:

a) Pengumpulan data dan pengecekan catatan lapangan.

b) Reduksi data, memilih dan memilah data yang relevan dan kurang relevan dengan tujuan penelitian, data yang relevan akan dianalisis dan data yang kurang relevan tidak dianalisis.

c) Penyajian data, meliputi: identifikasi, klasifikasi, penyusunan, penjelasan data secara sistematis, obyektif dan menyeluruh, serta pemaknaan.

d) Penyimpulan, peneliti menyimpulkan hasil penelitian berdasarkan kategori dan makna temuan. ${ }^{15}$

\footnotetext{
${ }^{15}$ Moh. Ainin, Metodologi Penelitian Bahasa Arab (Pasuruan: Hilal Pustaka, 2007),
} h. 125. 


\section{Pembahasan}

1. Problematika Penerapan Sistem Nazhariyah al Wahdah pada Pembelajaran Bahasa Arab

Alokasi waktu yang kurang memadai dan belum tersedianya laboratorium bahasa menjadi kendala umum bagi semua madrasah Aliyah di kota Metro ini. Hal ini berdampak pada pemahaman siswa yang belum menyeluruh. Para siswa dari 3 Madrasah Aliyah di kota Metro ini rata-rata hanya mampu menguasai mufrodat sebatas hafalan dan belum mampu mengaplikasikannya ke dalam bentuk kalimat lisan dan tulisan. Materi istima' belum bisa berjalan dengan maksimal karena pembelajaran hanya berlangsung di dalam kelas yang tidak kedap suara, sehingga suara yang dibunyikan kurang terdengar jelas. Begitu juga dengan materi qira'ah, siswa hanya mampu membaca teks namun belum mampu menerjemahkan teks ke dalam bahasa Indonesia yang baik dan benar. Dalam hal materi kitabah, siswa hanya mampu menyusun kata menjadi kalimat namun masih kesulitan untuk mengarang kalimat sederhana dengan kaidah penulisan bahasa Arab yang baik dan benar.

Problematika di atas selaras dengan hasil observasi peneliti ketika mengamati proses belajar mengajar bahasa Arab di dalam kelas. Sebagian besar guru hanya membaca dan menerjemahkan materi bahasa Arab, dan jika waktu pelajaran masih tersedia, proses ini dilanjutkan dengan menjawab tadribat atau latihan yang ada di dalam buku siswa. Alokasi waktu dan buku siswa yang telah ditentukan oleh Kementerian Agama membuat guru bahasa Arab tidak dapat berbuat banyak, guru harus mengejar target pembelajaran sehingga materi bahasa Arab dapat diselesaikan tepat waktu. Terjadinya proses pembelajaran ibarat air sungai yang mengalir tanpa henti mengejar 
permukaan yang lebih rendah, tanpa mempertimbangkan seberapa dalam siswa mampu memahami materi bahasa Arab.

\section{Solusi Problematika Penerapan Nazhariyah Al Wahdah}

Yang dapat menyelesaikan masalah ini adalah guru mata pelajaran bahasa Arab didukung oleh pihak sekolah. Guru harus mampu memahami dan menguasai problematika pengajaran bahasa Arab dengan baik sehingga guru mampu menemukan solusi. Ada beberapa hal yang harus dilakukan oleh guru dan pihak sekolah dalam menciptakan pembelajaran yang efektif dan efisien:

a) Guru mata pelajaran bahasa Arab adalah guru profesional yang memiliki keahlian di bidang pengajaran bahasa Arab. Seorang pengajar yang tidak mempunyai skill yang cukup tentu akan mengalami berbagai masalah yang yang serius dalam melaksanakan pembelajaran. Skill ini tidak hanya penguasaan terhadap materi tetapi juga kemampuan untuk melaksanakan proses pembelajaran yang baik dan benar. ${ }^{16}$ Posisi guru dalam pembelajaran bahasa sangatlah menentukan. Walaupun prasarana lengkap, metode dan strategi baik, tetapi jika guru tidak paham akan pembelajaran bahasa, maka pembelajaran akan gagal.

b) Pihak sekolah harus menyediakan lingkungan bahasa (bi'ah lughawiyah/bi'ah 'Arabiyah) dan guru harus membantu siswa dalam mempraktikkan bahasa Arab, dengan syarat: (1) Sikap dan apresiasi positif terhadap bahasa Arab dari pihak-pihak terkait seperti civitas akademika lembaga, mulai dari siswa sampai karyawan. (2) Pedoman yang jelas mengenai format dan model

\footnotetext{
${ }^{16}$ Yusuf al-Khalifah Abu Bakr, Nadwah Tathwir Baramij I'dad Muallimi al-Lughoh al-Arabiyyah lin Nathiqiina Bilughootin Uhkro (Sudan: Ma`had Khurtum al-Duali, 2000), h. 3-4.
} 
pengembangan pengembangan lingkungan berbahasa Arab. (3) Figur yang mampu berkomunikasi dengan bahasa Arab aktif, seperti guru native speaker. (4) Penyediaan alokasi dana yang memadai.

Belajar bahasa arab tidaklah sulit seperti yang dibayangkan kebanyakan orang. Banyak kiat dan tips yang bisa dilakukan, namun kunci utamanya adalah niat dan kemauan. Pepatah mengatakan "Dimana ada kemauan, di situ ada jalan", " Man jadda wajada", "When there is a will, there is a way". Maka, janganlah kita seperti orang yang tidak memiliki keinginan karena dianggap telah mati, dan orang yang memiliki keinginan tetapi tidak mempunyai target karena dianggap seperti orang gila, dan orang yang mempunyai target tetapi ia tidak mempunya usaha karena dianggap telah bermimpi.

\section{E. Simpulan}

Peneliti menyimpulkan bahwa alokasi waktu yang kurang memadai dan belum tersedianya laboratorium bahasa menjadi kendala umum bagi semua madrasah Aliyah di kota Metro. Hal tersebut berdampak pada siswa yang belum mampu memahami bagian-bagian materi bahasa Arab yang dijabarkan dalam hal berikut ini:

a) Materi mufradat, para siswa hanya mampu menguasai mufrodat sebatas hafalan dan belum mampu mengaplikasikannya ke dalam bentuk kalimat lisan dan tulisan.

b) Materi istima' belum bisa berjalan dengan maksimal karena pembelajaran hanya berlangsung di dalam kelas yang tidak kedap suara, sehingga suara yang dibunyikan kurang terdengar jelas. 
c) Materi qira'ah, siswa hanya mampu membaca teks namun belum mampu menerjemahkan teks ke dalam bahasa Indonesia yang baik dan benar.

d) Materi kitabah, siswa hanya mampu menyusun kata menjadi kalimat namun masih kesulitan untuk mengarang kalimat sederhana dengan kaidah penulisan bahasa Arab yang baik dan benar.

e) Untuk materi hiwar dan tarkib sebagian besar siswa sudah mampu menguasai 2 materi tersebut, karena pada materi ini siswa aktif mendemonstrasikan hiwar di depan kelas, dan mendiskusikan materi tarkib.

Dan untuk mengatasi permasalahan di atas, setidaknya sekolah harus mempunyai minimal dua hal berikut ini:

a) Guru mata pelajaran bahasa Arab profesional yang memiliki keahlian di bidang pengajaran bahasa Arab.

b) Lingkungan bahasa (bi'ah lughawiyah/ bi'ah 'Arabiyah). 


\section{Daftar Pustaka}

Ainin, Moh. Metodologi Penelitian Bahasa Arab. Pasuruan: Hilal Pustaka, 2007.

Asyrofi, Syamsuddin. Metodologi Pembelajaran Bahasa Arab. Yogyakarta: Idea Press, 2010.

Bakr, Yusuf al-Khalifah Abu. Nadwah Tathwir Baramij I'dad Muallimi alLughoh al-Arabiyyah lin Nathiqiina Bilughootin Uhkro. Sudan: Ma`had Khurtum al-Duali, 2000.

Damir. "Implementasi Naẓariyah al-Wahdah dalam Pembelajaran Bahasa Arab di SMA Islam Pekalongan.” Tesis, IAIN Walisongo, 2013. http://eprints.walisongo.ac.id/1481/.

Fachrurrozi, Aziz, dan Erta Mahyuddin. Teknik Pembelajaran Bahasa Arab. Bandung: Pustaka Cendikia Utama, 2011.

Iskandarwassid, dan Dadang Suhendar. Strategi Pembelajaran Bahasa. Bandung: PT. Remaja Rosdakarya, 2011.

Menteri Agama Republik Indonesia. "Peraturan Menteri Agama Republik Indonesia No. 912 Tahun 2013 tentang Kurikulum Madrasah 2013 Mata Pelajaran Pendidikan Agama Islam dan Bahasa Arab,” 2013.

Mudini. "Penerapan Nadzariyatul Wahdah Dalam Pengajaran Bahasa Arab Di Pondok Modern Assalam Kranggan Temanggung Jawa Tengah." Skripsi, UIN Sunan Kalijaga Yogyakarta, 2003. http://digilib.uinsuka.ac.id/9576/.

Mustofa, Muhammad Arif. "Asalibu Tadrisi Al-Lughah Al-'Arabiyah AlHaditsah.” An Nabighoh: Jurnal Pendidikan Dan Pembelajaran Bahasa Arab Vol. 18, no. 1 (2016). http://ejournal.metrouniv.ac.id/index.php/an-nabighoh/article/view/548.

Sholihatin, Laily. "Nadzariyatul Furu' dan Nadzariyatul Wahdah.” Makalah, Yogyakarta, 2013.

Sugiyono. Metode Penelitian Kuantitatif Kualitatif dan $R \& D$. Bandung: Alfabeta, 2009.

Taufiq, Najieb. “Tujuan Pembelajaran Bahasa Arab.” Diakses 24 Juni 2019. http://najiebtaufiq.blogspot.com/2012/06/tujuan-pembelajaranbahasa-arab.html.

Zulhannan. Paradigma Baru Pembelajaran Bahasa Arab. Bandar Lampung: An-Nur Press, 2004. 